УДК 658.382.3 : 622.276/279

\author{
РАНЖИРОВАНИЕ НАРУШЕНИЙ ТРЕБОВАНИЙ \\ ПРОМЫШЛЕННОЙ БЕЗОПАСНОСТИ И ОХРАНЫ ТРУДА \\ КАК ИНСТРУМЕНТ ПОВЫШЕНИЯ БЕЗОПАСНОСТИ \\ ОПАСНЫХ ПРОИЗВОДСТВЕННЫХ ОБЪЕКТОВ \\ НЕФТЕГАЗОДОБЫВАЮЩИХ ПРОИЗВОДСТВ
}

RANGING OF VIOLATIONS OF INDUSTRIAL SAFETY

AND OCCUPATIONAL HEALTH AND SAFETY REQUIREMENTS

AS A TOOL TO INCREASE THE SAFETY OF HAZARDOUS PRODUCTION FACILITIES OF OIL AND GAS PRODUCTION

Фатхутдинов Р.И.

Ухтинский государственный технический университет, г. Ухта, Российская Федерация

\title{
R.I. Fatkhutdinov
}

Uhta State Technological University, Uhta, Russian Federation

Аннотация. Нарушения требований промышленной безопасности и охраны труда являются одной из причин аварий, инцидентов и случаев производственного травматизма. Осуществляя производственный контроль на опасных производственных объектах нефтегазодобывающих производств, постоянно сталкиваешься с необходимостью оценить и ранжировать выявляемые нарушения по степени их опасности для объекта и работников эксплуатирующих организаций, а также возможных последствий для окружающей среды, в случаях незамедлительного устранения выявленных нарушений. 
Учитывая, что безопасность - это общее дело бизнеса, общества и государства, в настоящее время происходит активное внедрение системы риск-ориентированного подхода в деятельность Ростехнадзора. Рискориентированный подход представляет собой методологию, обеспечивающую целевое воздействие надзорных функций на объекты контроля, основанные на анализе состояния технических устройств, риска их аварий и инцидентов в соответствии со значимостью последствий таких аварий и инцидентов для безопасности и здоровья населения.

Внедрение риск-ориентированного подхода невозможно без вовлечения в данный процесс организаций, эксплуатирующих опасные производственные объекты. Оценку и анализ состояния опасных производственных объектов предлагается оценивать путем определения риск-ориентированного интегрального показателя уровня промышленной безопасности, для вычисления которого уже внедрена рассматриваемая в статье методика.

Данная методика довольно полно охватывает все аспекты соблюдения промышленной безопасности при эксплуатации опасных производственных объектов. Изучение методики позволило сделать вывод о недостаточном внимании, уделяемом качеству проведения контрольнопрофилактических проверок. При определении риск-ориентированного интегрального показателя уровня промышленной безопасности заполняются данные о количестве проверок и количестве выявленных и устраненных нарушениях требований безопасности, что не позволяет полноценно оценить уровень (ранг) выявленных нарушений требований безопасности по степени угрозы для объекта и работников эксплуатирующих организаций, а также для окружающей среды.

В статье приводятся данные об апробации на опасных производственных объектах нефтегазодобывающих производств предлагаемой методики определения ранга выявленных нарушений требований безопасности. 
Abstract. Violation of the requirements of industrial safety and occupational health and safety is one of the causes of accidents, incidents and occupational injuries. Carrying out production control at hazardous production facilities of oil and gas production facilities, you constantly face the need to assess and rank the detected violations in terms of their degree of danger to the facility and workers of operating organizations, as well as the possible consequences for the environment, in cases of immediate elimination of identified violations.

Given that safety is a common work of business, society and the state, there is currently an active introduction of a risk-based approach system into the activities of Rostekhnadzor. The risk-based approach is a methodology that provides the targeted impact of oversight functions on monitoring objects based on an analysis of the state of technical devices, the risk of their accidents and incidents in accordance with the significance of the consequences of such accidents and incidents for the safety and health of the population.

The introduction of a risk-based approach is impossible without the involvement of organizations operating hazardous production facilities in this process. Assessment and analysis of the state of hazardous production facilities is proposed to be evaluated by defining a risk-oriented integral index of the level of industrial safety, for calculation of which the methodology in question has been introduced.

This methodology covers quite enough all aspects of compliance with industrial safety, in the operation of hazardous production facilities. The study of the methodology, made it possible to conclude that the quality of the control and prophylactic checks was not enough. When determining the ROII IS, the data on the number of inspections and the number of detected and eliminated violations of security requirements are filled, which does not allow to fully assess the level (rank) of identified violations of safety requirements by the degree of threat to the facility and workers of operating organizations, as well as to the environment. 
The article contains data on approbation at the hazardous production facilities of oil and gas production facilities of the proposed methodology for determining the rank of the detected violations of safety requirements.

Ключевые слова: ранжирование нарушений, производственный контроль, риск-ориентированный подход, контрольно-профилактические проверки, промышленная безопасность, охрана труда.

Keywords: ranging of violations, production control, risk-oriented approach, control and prophylactic cheeks, industrial safety, occupational health and safety.

Последние 5-7 лет в Российской Федерации активно внедряется рискориентированный подход (РОП) к осуществлению надзорной деятельности $[1,2]$. Данный подход направлен на снижение административной нагрузки на бизнес без ущерба интересам общества и граждан. Одним из лидеров в данной области является Федеральная служба по экологическому, технологическому и атомному надзору (далее - Ростехнадзор) [3].

Несмотря на то, что государство ослабило нагрузку на бизнес, нельзя сказать, что с предприятий, эксплуатирующих опасные производственные объекты (ОПО) сняты требования по соблюдению требований промышленной безопасности и охраны труда. При риск-ориентированном надзоре актуальным являются определение опасности ОПО и своевременное выявление возможных аварий, инцидентов и несчастных случаев на них. Для решения указанной задачи Ростехнадзор планирует определять риск-ориентированный интегральный показатель уровня промышленной безопасности (РОИП ПБ) ОПО, для вычисления которого уже внедрена методика [1]. Эта методика довольно полно охватывает все аспекты соблюдения промышленной безопасности на ОПО, но в ней недостаточно уделено внимание качеству проведения проверок Ростехнадзором и контрольно-профилактических проверок предприятия. 
Это отражается в том, что при определении РОИП ПБ заполняются данные лишь о количестве проверок, выявленных и устраненных нарушениях.

К сожалению, данные критерии не дают полной картины для оценки качественного состава выявленных нарушений. При этом как для Ростехнадзора, представляющего интересы государства, так и для эксплуатирующей организации, важно в полной мере выявлять все имеющиеся нарушения на ОПО, ранжировать их по степени опасности и важности, проводить анализ, принимать корректирующие и предупреждающие меры, и в конечном счете не допускать аварии, инциденты и несчастные случаи на указанных объектах $[4,5]$.

Таким образом, одним из способов, позволяющим повысить результативность проверок на ОПО, является ранжирование нарушений, выявленных при проверках, и определение приоритетов по их устранению.

Для выполнения ранжирования предлагается Методика определения показателя ранга нарушения и группы нарушений, разработанного при помощи экспертной оценки. При этом, исходя из показателей ранга нарушения, предприятие определяет для себя приоритеты для устранения выявленного нарушения.

Итак, для определения опасности, важности и срочности каждого нарушения необходимо выявить характеристики нарушения, которые влияют на указанные показатели. По результатам анализа статистических данных Ростехнадзора и опроса экспертов были определены следующие основные характеристики нарушений:

1. Тяжесть последствий аварий, инцидентов, производственного травматизма;

2. Вероятность возникновения аварии;

3. Вероятность возникновения инцидента;

4. Вероятность наступления производственного травматизма;

5. Затраты на устранение последствий аварии/ инцидента/ производственного травматизма; 
6. Затраты на устранение нарушения;

7. Время, необходимое для устранения нарушения;

8. Повторяемость нарушения при проверках;

9. Отсутствие изменения тяжести последствий и вероятности возникновения аварии / инцидента / производственного травматизма от нарушения с течением времени (отсутствие накопительного эффекта).

Далее для каждой из указанных характеристик определены диапазоны возможных значений с указанием того, является ли это значение «хорошим», «удовлетворительным» или «плохим»в нашем понимании. При это значениям «хорошо», «удовлетворительно» или «плохо» установлены баллы 1, 2 и 3 соответственно (таблица 1).

Далее необходимо определить эти характеристики для выявленных нарушений. Однако характеристики по своей важности, приоритетности, срочности неравнозначны. Поэтому сначала необходимо определить важность отдельных характеристик. Для этого важность каждой характеристики нарушения принята в условных единицах, принимающих значение от 1 до 10 (таблица 2).

Значение показателя ранга $m$-го нарушения $\left(\mathrm{\Pi PH}_{m}\right)$ определяется суммированием умноженных значений критерия каждой характеристики $\left(\mathrm{K}_{n}\right)$ на важность этой характеристики $\left(\mathrm{B}_{n}\right)$ и делением на сумму важности характеристик:

$$
\Pi_{\mathrm{P}}=\sum_{1}^{\mathrm{n}} \frac{\mathrm{B}_{n} \times \mathrm{K}_{n}}{\mathrm{~B}_{n}},
$$

где $\mathrm{B}_{n}-$ важность $n$-ой характеристики, $\kappa_{n}-$ критерий $n$-ой характеристики. 
Таблица 1. Критерии для оценки опасности и важности нарушения

\begin{tabular}{|c|c|c|c|}
\hline \multirow[b]{2}{*}{ Характеристика } & \multicolumn{3}{|c|}{ Критерии $\left(\kappa_{n}\right)$} \\
\hline & Плохо & $\begin{array}{c}\text { Удовлетворительн } \\
\text { о }\end{array}$ & Хорошо \\
\hline Баллы & 3 & 2 & 1 \\
\hline $\begin{array}{l}\text { Тяжесть последствий аварий, } \\
\text { инцидентов, производственного } \\
\text { травматизма }\end{array}$ & $\begin{array}{l}\text { Остановка } \\
\text { технического } \\
\text { устройства/оборудо } \\
\text { вания/ОПО до } \\
\text { выяснения причин }\end{array}$ & $\begin{array}{l}\text { Возможно } \\
\text { продолжение работ } \\
\text { после ремонта }\end{array}$ & $\begin{array}{l}\text { Продолжение } \\
\text { работ без } \\
\text { остановки } \\
\text { технического } \\
\text { устройства/обо } \\
\text { рудования/ОП } \\
\text { О }\end{array}$ \\
\hline $\begin{array}{l}\text { Вероятностьвозникновения } \\
\text { аварии }\end{array}$ & Крайне высокая & Скорее да, чем нет & $\begin{array}{l}\text { Скорее нет, } \\
\text { чем да }\end{array}$ \\
\hline $\begin{array}{l}\text { Вероятность возникновения } \\
\text { инцидента }\end{array}$ & Крайне высокая & Скорее да, чем нет & $\begin{array}{l}\text { Скорее нет, } \\
\text { чем да }\end{array}$ \\
\hline $\begin{array}{l}\text { Вероятность наступления } \\
\text { производственного } \\
\text { травматизма }\end{array}$ & Крайне высокая & Скорее да, чем нет & $\begin{array}{l}\text { Скорее нет, } \\
\text { чем да }\end{array}$ \\
\hline $\begin{array}{l}\text { Затраты на устранение } \\
\text { последствий аварии/ } \\
\text { инцидента/ производственного } \\
\text { травматизма }\end{array}$ & Более 1 млн руб. & $\begin{array}{l}\text { От } 50 \text { тыс. руб. до } 1 \\
\text { млн руб. }\end{array}$ & $\begin{array}{l}\text { Менее } 50 \text { тыс. } \\
\text { руб. }\end{array}$ \\
\hline $\begin{array}{l}\text { Затраты на устранение } \\
\text { нарушения }\end{array}$ & Более 100 тыс. руб. & $\begin{array}{l}\text { От } 5 \text { тыс. руб. до } \\
100 \text { тыс. руб. }\end{array}$ & $\begin{array}{l}\text { Менее } 5 \text { тыс. } \\
\text { руб. }\end{array}$ \\
\hline $\begin{array}{l}\text { Время, необходимое для } \\
\text { устранения нарушения }\end{array}$ & Более 1 года & $\begin{array}{l}\text { От } 1 \text { месяца до } 1 \\
\text { года }\end{array}$ & До 1 месяца \\
\hline $\begin{array}{l}\text { Повторяемость нарушения при } \\
\text { проверках }\end{array}$ & $\begin{array}{l}\text { Повторяется более } \\
3 \text { раз }\end{array}$ & $\begin{array}{l}\text { Повторяется от } 1 \\
\text { до } 3 \text { раз }\end{array}$ & Не повторяется \\
\hline $\begin{array}{l}\text { Отсутствие изменения тяжести } \\
\text { последствий и вероятности } \\
\text { возникновения } \\
\text { аварий/инцидентов/производст } \\
\text { венного травматизма от } \\
\text { нарушения с течением времени } \\
\text { (отсутствие накопительного } \\
\text { эффекта) }\end{array}$ & $\begin{array}{l}\text { Со временем } \\
\text { повышается } \\
\text { уровень риска }\end{array}$ & $\begin{array}{l}\text { Возможно } \\
\text { повышение уровня } \\
\text { риска }\end{array}$ & $\begin{array}{l}\text { Не меняет } \\
\text { уровня риска } \\
\text { по времени }\end{array}$ \\
\hline
\end{tabular}

Таблица 2. Важность характеристик нарушения

\begin{tabular}{|l|c|}
\hline \multicolumn{1}{|c|}{ Характеристика } & $\begin{array}{c}\text { Важность } \\
\text { характеристи } \\
\text { ки (В } \mathbf{n} \text { ),усл. ед. }\end{array}$ \\
\hline Тяжесть последствий аварий, инцидентов, производственного травматизма & 7 \\
\hline Вероятность возникновения аварии & 10 \\
\hline Вероятность возникновения инцидента & 5 \\
\hline Вероятность наступления производственного травматизма & 9 \\
\hline $\begin{array}{l}\text { Затраты на устранение последствий аварии/ инцидента/ производственного } \\
\text { травматизма }\end{array}$ & 7 \\
\hline Затраты на устранение нарушения & 6 \\
\hline Время, необходимое для устранения нарушения & 3 \\
\hline Повторяемость нарушения при проверках & 2 \\
\hline $\begin{array}{l}\text { Отсутствие изменения тяжести последствий и вероятности возникновения } \\
\text { аварий/инцидентов/производственного травматизма от нарушения с } \\
\text { течением времени (отсутствие накопительного эффекта) }\end{array}$ \\
\hline
\end{tabular}


Для того, чтобы полученное числовое значение ПРН ${ }_{m}$ связать с лингвистическими переменными, внедрены матрицы перехода по 2 критериям:

- влияние на уровень промышленной безопасности,

- «важность - срочность» нарушения (таблица 3).

Таблица 3. Матрица перехода для связи показателя ранга $m$-го нарушения с лингвистической переменной по критерию влияния на уровень промышленной безопасности и критерию «важность - срочность»

\begin{tabular}{|l|l|l|}
\hline \multirow{2}{*}{$\begin{array}{c}\text { Диапазон } \\
\text { числовых } \\
\text { значений ПРН }\end{array}$} & \multicolumn{2}{|c|}{$\begin{array}{c}\text { Лингвистическая переменная, характеризующая показатели с точки } \\
\text { зрения: }\end{array}$} \\
\cline { 2 - 3 } & $\begin{array}{c}\text { влияния на уровень } \\
\text { промышленной безопасности }\end{array}$ & \multicolumn{1}{|c|}{ «важность-срочность» } \\
\hline $2,6-3,0$ & Практический не влияет & Не важно - Не срочно \\
\hline $2,2-2,6$ & Небольшое влияние & Неважно - Срочно \\
\hline $1,8-2,2$ & Удовлетворительное влияние & \\
\hline $1,4-1,8$ & Сильное влияние & \multirow{2}{*}{ Важно - Срочно } \\
\hline $1,0-1,4$ & Очень сильное влияние & \\
\hline
\end{tabular}

Лингвистическая переменная «Практический не влияет» показывает, что нарушение, незначительное с точки зрения влияния на уровень промышленной безопасности и охраны труда, соответственно риск возникновения аварий, инцидентов и производственного травматизма минимален.

Лингвистическая переменная «Очень сильное влияние» показывает, что нарушение значительное с точки зрения влияния на уровень промышленной безопасности и охраны труда, соответственно риск возникновения аварий, инцидентов и производственного травматизма максимален.

Остальные лингвистические переменные носят промежуточный характер.

По критерию «важность - срочность» лингвистические переменные от «важно - срочно» до «не важно - срочно» показывают очередность устранения нарушения, где нарушения «важно - срочно» необходимо устранять в первую очередь. 
Указанная выше методика позволяет определить показатель ранга каждого нарушения. Но необходимо также учитывать, что при проведении проверок на ОПО выявляется множество нарушений, каждое из которых имеет свою степень влияния на уровень промышленной безопасности и охраны труда объекта. Это множество нарушений, выявленных для элемента ОПО, может иметь накопительный эффект и привести к определённым последствиям. Под элементами ОПО в данном случае подразумеваются технические устройства, сооружения и т.д. [6]. Таким образом, очевидно, что кроме (ПРН) ля ранга нарушения важно учитывать и определять показатель ранга группы нарушений i-го элемента ОПО (ПРГНі).

Выявленный при этом показатель ранга группы нарушений i-го элемента ОПО позволяет определять уровень влияния і-го элемента ОПО на безопасность ОПО в целом и распределять силы по принятию корректирующих мер с учетом показателя ранга группы нарушений.

Для определения показателя ранга группы нарушений і-го элемента ОПО предлагается определять важность показателя ранга m-го нарушения, принятой в неких условных единицах, принимающих значение от 1 до 10 (таблица 4).

Таблица 4. Важность Показателя ранга $m$-гонарушения

\begin{tabular}{|c|c|c|}
\hline $\begin{array}{c}\text { Диапазон } \\
\text { числовых } \\
\text { значений ПРН }\end{array}$ & $\begin{array}{c}\text { Лингвистическая переменная, } \\
\text { характеризующая показатели с точки зрения } \\
\text { влияния на уровень промышленной } \\
\text { безопасности }\end{array}$ & $\begin{array}{c}\text { Важность } \\
\text { показателя ранга } \\
\text { нарушения }\left(\mathrm{B}_{\boldsymbol{m}}\right)\end{array}$ \\
\hline $2,6-3,0$ & Практический не влияет & 2 \\
\hline $2,2-2,6$ & Небольшое влияние & 4 \\
\hline $1,8-2,2$ & Удовлетворительно влияние & 6 \\
\hline $1,4-1,8$ & Сильное влияние & 8 \\
\hline $1,0-1,4$ & Очень сильное влияние & 10 \\
\hline
\end{tabular}

На основании распределения выявленных нарушений по таблице 4 и с учетом важности каждого показателя нарушения $\mathrm{B}_{m}$, определяется 
Показатель ранга группы нарушений $\left(П Р Г \mathrm{H}_{i}\right)$ для конкретного элемента ОПО:

$$
\text { ПРГН } \mathrm{H}_{i}=\sum_{1}^{i} \frac{\mathrm{B}_{\mathrm{m}} \times \mathrm{K}_{\mathrm{m}}}{\mathrm{B}_{\mathrm{m}}},
$$

где $\mathrm{B}_{m}$ - важность показателя ранга $m$-го нарушения, $\Pi \mathrm{PH}_{m}$ - показатель ранга $m$-го нарушения.

Полученное числовое значение ПРГН $i$-го элемента ОПО аналогично классифицируется с лингвистическими переменными по матрице перехода, указанного в таблице 3.

Таким образом, в указанной выше Методике определения показателя ранга нарушения и группы нарушений предлагается подход ранжирования нарушений, который можно использовать для таких ОПО нефтегазодобывающих производств, как фонды скважин, системы межпромысловых и промысловых трубопроводов, площадочные объекты подготовки и перекачки нефти. При этом, определив один раз ПРН типовых нарушений при проведении проверок, в дальнейшем ПРН этих нарушений будет известен заранее.

Также актуальной является интеграция ПРН типовых нарушений в карты контроля объектов нефтедобывающих производств. При этом полученные в соответствии с методикой значения ПРН типовых нарушений отражаются в картах контроля напротив каждого типового нарушения [2].

Практическое применение таких карт контроля с интегрированными в них ПРН каждого типового нарушения на ОПО нефтедобывающих производств позволяет существенно повысить результативность контрольно-профилактических проверок на ОПО нефтедобывающих производств [7].

На рисунке 1 показан пример заполнения карты контроля с показателями ранга нарушения ПРН для проведения проверки 
автоматизированной групповой замерной установки (АГЗУ) и дренажных

\title{
емкостей на фонде скважин месторождения.
}

Карта контроля проведения проверки АГЗУ и Дренажных емкостей

Цех № 5

Месторождение Баварлинское

№ площадки скважины (куста) 15

№ АГЗУ $15-\mathrm{K}$

ФИО проверяющего Иванов Петр Семенович

Дата заполнения 15.08.2017

Данные геолокации (географического местоположения) объекта

Инструкция по заполнению таблицы:

1. Сведения заполняются ручкой, печатным шрифтом.

2. Достоверность данных подтверждается фотоматериалами.

3. Отметки ставятся:

+ - в случае подтверждения нарушений из столбца 2 фактической обстановке;

- - в случае неподтверждения нарушений из столбца 2 фактической обстановке;

о - в случае отсутствия или неприменимости данного вида нарушений из столбца 2 фактической обстановке.

\begin{tabular}{|c|c|c|c|c|}
\hline $\begin{array}{l}\text { № } \\
\end{array}$ & $\begin{array}{c}\text { Перечень возможных несоответствий } \\
\text { (характер возможных нарушений требований промышленной безопасности) }\end{array}$ & $\begin{array}{c}\text { Нормативные } \\
\text { документы и } \\
\text { их пункть }\end{array}$ & $\begin{array}{c}\text { Показатель } \\
\text { ранга } \\
\text { нарушения } \\
\text { ПРН }\end{array}$ & $\begin{array}{c}\text { Отметка } \\
(+/-/ \mathrm{o})\end{array}$ \\
\hline & АГЗУ (Наружная сторона) & & & \\
\hline 1 & $\begin{array}{l}\text { Отсутствует информационный щит с указанием наименования объекта и } \\
\text { владельца, номера контактного телефона, с указанием регистрационного } \\
\text { номера о регистрации ОПО в государственном реестре. }\end{array}$ & п. 9 ФНП ПБ НГП & 2,9 & - \\
\hline 2 & $\begin{array}{l}\text { На информационном щите информация отсутствует информация: } \\
\text { - о наименовании объекта. }\end{array}$ & п. 9 ФНП ПБ НГП & 2,95 & - \\
\hline 3 & - о владельце объекта. & п. 9 ФНП ПБ НГП & 2,95 & - \\
\hline 4 & - о номере контактного телефона. & п. 9 ФНП ПБ НГП & 2,95 & - \\
\hline 5 & $\begin{array}{l}\text { - о регистрационном номере о регистрации ОПО в государственном } \\
\text { реестре. }\end{array}$ & п. 9 ФНП ПБ НГП & 2,95 & - \\
\hline
\end{tabular}

\begin{tabular}{|c|c|c|c|c|}
\hline 37 & Отсутствует (неисправна) система вентиляции АГЗУ. & $\begin{array}{l}\text { п. } 549 \text { ФНП ПБ } \\
\text { НГП }\end{array}$ & 1,56 & + \\
\hline 38 & АГЗУ не имеет защитного заземления. & $\begin{array}{l}\text { п. } 81 \text { ФНП ПБ } \\
\text { НГП }\end{array}$ & 2,1 & - \\
\hline \multirow[t]{2}{*}{39} & $\begin{array}{l}\text { Рядом с элементом присоединения заземленияк АГЗУ отсутствует } \\
\text { изображение символа «Заземление». }\end{array}$ & $\begin{array}{l}\text { п. } 81 \text { ФНП ПБ } \\
\text { НГП } \\
\text { п. } 3.3 .5 \text { ГОСТ } \\
12.2 .007 .0-75\end{array}$ & 2,89 & - \\
\hline & АГЗУ (Внутренняя сторона) & & & \\
\hline 1 & $\begin{array}{l}\text { Отсутствует схема технологического процесса, утвержденная } \\
\text { техническим руководителем организации, с указанием номеров задвижек, } \\
\text { аппаратов, направлений потоков, полностью соответствующих их } \\
\text { нумерации в проектной документации. }\end{array}$ & $\begin{array}{l}\text { п. } 553 \text { ФНП ПБ } \\
\quad \text { НГП }\end{array}$ & 1,8 & + \\
\hline 2 & \begin{tabular}{|l} 
Средства аварийной сигнализации, контроля возгораний и состояния \\
воздушной среды, установленные в соответствии с проектной \\
документацией, отсутствуют или находятся в неисправном состоянии.
\end{tabular} & $\begin{array}{l}\text { П.3.3.3 ППБО- } 85 \\
\text { П. } 395 \text { ФНП ПБ } \\
\text { НГП }\end{array}$ & 1,15 & + \\
\hline 3 & $\begin{array}{l}\text { Электрооборудование (машины, аппараты, устройства), контрольно- } \\
\text { измерительные приборы, электрические светильники, средства } \\
\text { блокировки, сигнальные устройства к ним не выполнены во } \\
\text { взрывозащищенном исполнении и не имеют уровень взрывозащиты в } \\
\text { соответствии с Техническим регламентом о требованиях пожарной } \\
\text { безопасности N 123-Ф3, вид взрывозащиты - категории и группе } \\
\text { взрывоопасной смеси. }\end{array}$ & $\begin{array}{l}\text { п. } 90 \text { ФНП ПБ } \\
\text { НГП }\end{array}$ & 1,4 & + \\
\hline 4 & Корпус электродвигателя вентилятора не имеет защитного заземления. & $\begin{array}{c}\text { п. } 81 \text { ФНП ПБ } \\
\text { НГП }\end{array}$ & 2,3 & - \\
\hline
\end{tabular}

\section{Рисунок 1. Пример использования карты контроля с ПРН для проведения} проверки АГЗУ и дренажных емкостей на фонде скважин месторождения

\section{В ходе проверки АГЗУ выявлено 4 нарушения, ПРН каждого из них}

\author{
отмечен желтой заливкой.
}


На нарушениях, выявленных при проведении проверки АГЗУ, рассмотрим применимость Методики определения показателя ранга нарушения и группы нарушений.

\section{Пример № 1.}

Определение ПРН для нарушения, выявленного в ходе контрольно-профилактической проверки ОПО нефтегазодобывающего производства.

Пример нарушения, связанного с неисправной системой вентиляции в АГЗУ на фонде скважин месторождения, представлен в таблице 5.

Таблица 5. Пример нарушения, связанного с неисправной системой вентиляции в АГЗУ на фонде скважин месторождения

\begin{tabular}{|c|c|}
\hline Наименование нарушения & Ссылка на нормативно-правовой документ \\
\hline $\begin{array}{l}\text { Отсутствует (не исправна) } \\
\text { система вентиляции АГЗУ. }\end{array}$ & $\begin{array}{l}\text { Федеральные нормы и } \\
\text { промышленной безопасности «Правила } \\
\text { нефтяной и гезопасности в } \\
\text { Приказом Ростехнадзора от о } 12.03 .2013 \text { г. № } 101 \text { (с } \\
\text { изменениями и дополнениями), пункт } 549\end{array}$ \\
\hline
\end{tabular}

Эman № 1. Определяем соответствующие критерии по каждой характеристике (отмечены зеленой заливкой) (таблица 6). 
Таблица 6. Определение критериев нарушения по каждой характеристике

\begin{tabular}{|c|c|c|c|}
\hline \multirow{2}{*}{ Характеристика } & \multicolumn{3}{|c|}{ Критерии $\left(\mathbf{K}_{i}\right)$} \\
\hline & Плохо & Удовлетворительно & Хорошо \\
\hline Баллы & 3 & 2 & 1 \\
\hline $\begin{array}{l}\text { Тяжесть последствий аварий, } \\
\text { инцидентов, производственного } \\
\text { травматизма }\end{array}$ & $\begin{array}{l}\text { Остановка } \\
\text { технического } \\
\text { устройства/ } \\
\text { оборудования/ ОПО } \\
\text { до выяснения причин }\end{array}$ & $\begin{array}{l}\text { Возможно } \\
\text { продолжение } \\
\text { после ремонта }\end{array}$ & $\begin{array}{l}\text { Продолжени } \\
\text { е работ без } \\
\text { остановки } \\
\text { техническог } \\
\text { о } \\
\text { устройства/ } \\
\text { оборудован } \\
\text { ия/ОПО }\end{array}$ \\
\hline $\begin{array}{l}\text { Вероятность возникновения } \\
\text { аварии }\end{array}$ & Крайне высокая & Скорее да, чем нет & $\begin{array}{l}\text { Скорее нет, } \\
\text { чем да }\end{array}$ \\
\hline $\begin{array}{l}\text { Вероятность возникновения } \\
\text { инцидента }\end{array}$ & Крайне высокая & Скорее да, чем нет & $\begin{array}{l}\text { Скорее нет, } \\
\text { чем да }\end{array}$ \\
\hline $\begin{array}{l}\text { Вероятность наступления } \\
\text { производственного } \\
\text { травматизма }\end{array}$ & Крайне высокая & Скорее да, чем нет & $\begin{array}{l}\text { Скорее нет, } \\
\text { чем да }\end{array}$ \\
\hline $\begin{array}{l}\text { Затраты на } \\
\begin{array}{l}\text { последствий } \\
\text { инцидента/ пронанение } \\
\text { травматизма }\end{array}\end{array}$ & Более 1 млн. руб. & $\begin{array}{l}\text { От } 50 \text { тыс. руб. до } 1 \\
\text { млн. руб. }\end{array}$ & $\begin{array}{l}\text { Менее } 50 \\
\text { тыс. руб. }\end{array}$ \\
\hline $\begin{array}{lll}\text { Затраты } & \text { на } & \text { устранение } \\
\text { нарушения } & & \end{array}$ & Более 100 тыс. руб. & $\begin{array}{l}\text { От } 5 \text { тыс. руб. до } 100 \\
\text { тыс. руб. }\end{array}$ & $\begin{array}{ll}\text { Менее } & 5 \\
\text { тыс. руб. } & \end{array}$ \\
\hline $\begin{array}{l}\text { Время, необходимое } \\
\text { устранения нарушения }\end{array}$ & Более 1 года & $\begin{array}{llll}\text { От } 1 \text { месяца до } & 1 \\
\text { года }\end{array}$ & До 1 месяца \\
\hline $\begin{array}{l}\text { Повторяемость нарушения при } \\
\text { проверках }\end{array}$ & $\begin{array}{l}\text { Повторяется более } 3 \\
\text { раз }\end{array}$ & $\begin{array}{l}\text { Повторяется от } 1 \text { до } \\
3 \text { раз }\end{array}$ & $\begin{array}{l}\text { Не } \\
\text { повторяется }\end{array}$ \\
\hline $\begin{array}{l}\text { Отсутствие изменения тяжести } \\
\text { последствий и вероятности } \\
\text { возникновения } \\
\text { аварий/инцидент/производстве }\end{array}$ & $\begin{array}{lr}\text { Со } & \text { временем } \\
\text { повышается } & \text { уровень } \\
\text { риска } & \end{array}$ & $\begin{array}{l}\text { Возможно } \\
\text { повышение } \\
\text { риска }\end{array}$ & $\begin{array}{l}\text { Не меняет } \\
\text { уровня } \\
\text { риска по по } \\
\text { впемени }\end{array}$ \\
\hline $\begin{array}{lr}\text { нного } & \text { травматизма } \\
\text { нарушения с течением времени } \\
\text { (отсутствие } \\
\text { эффекта) }\end{array}$ & & & \\
\hline
\end{tabular}

Эman № 2. На основании выбора критериев характеристики и установления баллов 3, 2 и 1 для «плохо», «удовлетворительно» и «хорошо» соответственно характеристики нарушения будут выглядеть следующим образом (таблица 7). 
Таблица 7. Установление баллов критериев нарушения по каждой характеристике

\begin{tabular}{|c|c|}
\hline Характеристика & Критерии $\left(\boldsymbol{K}_{i}\right)$ \\
\hline $\begin{array}{l}\text { Тяжесть последствий аварий, инцидентов, производственного } \\
\text { травматизма }\end{array}$ & 1 \\
\hline Вероятностьвозникновения аварии & 1 \\
\hline Вероятность возникновения инцидента & 2 \\
\hline Вероятность наступления производственного травматизма & 3 \\
\hline $\begin{array}{l}\text { Затраты на устранение последствий } \\
\text { производственного травматизма }\end{array}$ & 2 \\
\hline Затраты на устранение нарушения & 1 \\
\hline Время, необходимое для устранения нарушения & 1 \\
\hline Повторяемость нарушения при проверках & 2 \\
\hline $\begin{array}{l}\text { Отсутствие изменения тяжести последствий и вероятности } \\
\text { возникновения } \\
\text { травматизма от нарушения с течением времени (отсутствие } \\
\text { накопительного эффекта) }\end{array}$ & 1 \\
\hline
\end{tabular}

Эman № 3. В связи с тем, что каждая характеристика имеет важность, из таблицы 7 получим следующие значения (таблица 8).

Таблица 8. Определение критериев нарушения по каждой характеристике с учетом важности

\begin{tabular}{|c|c|c|c|}
\hline Характеристика & $\begin{array}{c}\text { Критерии } \\
\left(\kappa_{i}\right)\end{array}$ & $\begin{array}{c}\text { Важность } \\
\text { (Вi) }\end{array}$ & $\begin{array}{c}\text { Критерии }\left(K_{i}\right) \\
\text { с учетом } \\
\text { Важности }\left(\mathrm{B}_{i}\right),\end{array}$ \\
\hline $\begin{array}{l}\text { Тяжесть последствий аварий, инцидентов, } \\
\text { производственного травматизма }\end{array}$ & 1 & 7 & 7 \\
\hline Вероятность возникновения аварии & 1 & 10 & 10 \\
\hline Вероятность возникновения инцидента & 2 & 5 & 10 \\
\hline $\begin{array}{l}\text { Вероятность } \\
\text { производственного травматизма }\end{array}$ & 3 & 10 & 30 \\
\hline $\begin{array}{l}\text { Затраты на устранение последствий аварии/ } \\
\text { инцидента/ производственного травматизма }\end{array}$ & 2 & 9 & 18 \\
\hline Затраты на устранение нарушения & 1 & 7 & 7 \\
\hline $\begin{array}{l}\text { Время необходимое для устранения } \\
\text { нарушения }\end{array}$ & 1 & 6 & 6 \\
\hline Повторяемость нарушения при проверках & 2 & 3 & 2 \\
\hline 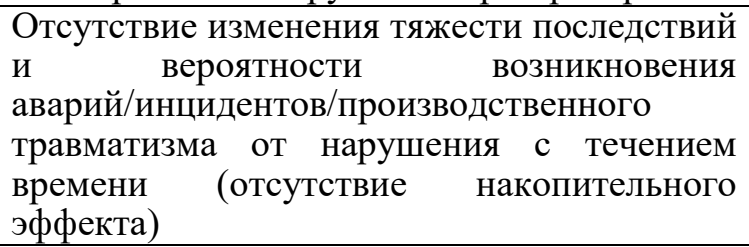 & 1 & 2 & 2 \\
\hline
\end{tabular}


Эman № 4. На основании вышеуказанных действий определяем показатель ранга нарушения:

$$
\Pi \text { ПН }=\frac{7+10+10+30+18+7+6+2+2}{7+10+5+10+9+7+6+3+2}=\frac{92}{59}=1,56 .
$$

Этаn № 5. Устанавливаем связь между числовым значением ПРН и лингвистическими переменными по критерию влияния на уровень промышленной безопасности и критерию «важность - срочность» по матрице перехода (таблица 9).

Таблица 9. Матрица перехода для связи ПРН с лингвистической переменной по критерию влияния на уровень промышленной безопасности и критерию «важность - срочность»

\begin{tabular}{|l|l|l|}
\hline \multirow{2}{*}{$\begin{array}{c}\text { Диапазон } \\
\text { числовых } \\
\text { значений ПРН } \\
\text { и ПРГН }\end{array}$} & \multicolumn{2}{|c|}{$\begin{array}{c}\text { Лингвистическая переменная, характеризующая показатели } \\
\text { с точки зрения: }\end{array}$} \\
\cline { 2 - 3 } & \multicolumn{1}{|c|}{$\begin{array}{c}\text { влияния на уровень } \\
\text { промышленной безопасности }\end{array}$} & $\begin{array}{c}\text { по критерию «важность- } \\
\text { срочность» }\end{array}$ \\
\hline $2,6-3,0$ & Практический не влияет & Не важно - Не срочно \\
\hline $2,2-2,6$ & Небольшое влияние & Неважно - Срочно \\
\hline $1,8-2,2$ & Удовлетворительно влияние & \\
\hline $1,4-1,8$ & Сильное влияние & Важно - Срочно \\
\hline $1,0-1,4$ & Очень сильное влияние & \\
\hline
\end{tabular}

Итак, для нарушения, связанного с неисправной системой вентиляции АГЗУ, числовое значение ПРН равно 1,56. По лингвистическим переменным данное значение соответствует:

- с точки зрения влияния на уровень промышленной безопасности «Сильное влияние»;

- с точки зрения важности-срочности - «Важно - Срочно».

С учетом указанных лингвистических переменных данное нарушение следует устранить в первую очередь и в максимально сжатые сроки. 


\section{Пример № 2.}

Определение ПРГН для нарушений, выявленных в ходе $\begin{array}{lll}\text { контрольно-профилактической } & \text { пГЗУ }\end{array}$ нефтегазодобывающего предприятия.

При проверке АГЗУ выявлено 4 нарушения. С учетом методики для каждого нарушения определены показатели ранга нарушения ПРН, указанные на рисунке 1.

Этап № 1. Заполняем полученные показатели ранга каждого нарушения с учетом диапазонов (таблица 10).

Таблица 10. Определение важности нарушений с учетом диапазонов

\begin{tabular}{|c|c|c|c|c|c|c|}
\hline \multirow{2}{*}{$\begin{array}{l}\text { Диапазон } \\
\text { числовых } \\
\text { значений } \\
\text { ПРН }\end{array}$} & \multirow[b]{2}{*}{$\begin{array}{l}\text { Лингвистическая } \\
\text { переменная, } \\
\text { характеризующая } \\
\text { показатели с точки зрения } \\
\text { влияния на уровень } \\
\text { промышленной } \\
\text { безопасности } \\
\end{array}$} & \multirow[b]{2}{*}{$\begin{array}{c}\text { Важность } \\
\text { показателя } \\
\text { ранга } \\
\text { нарушения } \\
\left(\mathrm{B}_{m}\right)\end{array}$} & \multicolumn{4}{|c|}{ ПРН } \\
\hline & & & $\begin{array}{c}\text { Hapy- } \\
\text { шение } \\
1\end{array}$ & $\begin{array}{l}\text { Нару- } \\
\text { шение } \\
2\end{array}$ & $\begin{array}{l}\text { Нару- } \\
\text { шение } \\
\mathbf{3}\end{array}$ & $\begin{array}{c}\text { Hapy- } \\
\text { шение } \\
4\end{array}$ \\
\hline $2,6-3,0$ & Практический не влияет & 2 & & & & \\
\hline $2,2-2,6$ & Небольшое влияние & 4 & & 1,8 & & \\
\hline $1,8-2,2$ & Удовлетворительно влияние & 6 & & & & \\
\hline $1,4-1,8$ & Сильное влияние & 8 & 1,56 & & & \\
\hline $1,0-1,4$ & Очень сильное влияние & 10 & & & 1,15 & 1,4 \\
\hline
\end{tabular}

Этап № 2. На основании вышеуказанных действий определяем ПРГН для АГЗУ:

$$
\text { ПРГН }=\frac{4 \times 1,8+8 \times 1,56+10 \times 1,15+10 \times 1,4}{4+8+10+10}=\frac{44,7}{32}=1,4 .
$$

Устанавливаем связь между числовым значением ПРГН для АГЗУ и лингвистическими переменными по критерию влияния на уровень промышленной безопасности по матрице перехода (таблица 11). 
Таблица 11. Матрица перехода для связи ПРГН с лингвистической переменной по критерию влияния на уровень промышленной безопасности и критерию «Важность - Срочность»

\begin{tabular}{|l|l|l|}
\hline $\begin{array}{l}\text { Диапазон } \\
\text { числовых } \\
\text { значений ПРН и й } \\
\text { ПРГН }\end{array}$ & \multicolumn{2}{|c|}{$\begin{array}{c}\text { Лингвистическая переменная, характеризующая показатели с точки } \\
\text { зрения: }\end{array}$} \\
\cline { 2 - 3 } проминия на уровень & \multicolumn{1}{|c|}{$\begin{array}{c}\text { по критерию «важность- } \\
\text { срочность» }\end{array}$} \\
\hline $2,6-3,0$ & Практический не влияет & Важно - Несрочно \\
\hline $2,2-2,6$ & Небольшое влияние & Неважно - Срочно \\
\hline $1,8-2,2$ & Удовлетворительно влияние & \\
\hline $1,4-1,8$ & Сильное влияние & Важно-срочно \\
\hline $1,0-1,4$ & Очень сильное влияние & \\
\hline
\end{tabular}

Итак, для АГЗУ с выявленными при проверке 4 нарушениями числовое значение показателя ранга группы нарушений равно 1,4. По лингвистическим переменным данное значение соответствует:

- с точки зрения влияния на уровень промышленной безопасности «Очень сильное влияние»;

- с точки зрения важности-срочности - «Важно - Срочно».

С учетом указанных лингвистических переменных, если при сравнении ПРГН других технических устройств или сооружении меньше ПРГН АГЗУ, то следует устранить в первую очередь и в максимально сжатые сроки нарушения, выявленные при проверке АГЗУ.

\section{Выводы}

В статье предложена и описана Методика определения показателя ранга нарушения и группы нарушений, основанная на экспертной оценке, конечным результатом при использовании которой является ранжирование нарушения или группы нарушений элемента ОПО по 2 критериям:

- с точки зрения влияния на уровень промышленной безопасности;

- с точки зрения важности-срочности.

В свою очередь, ранжирование нарушений позволяет: 
- определять влияние выявленного в ходе проверки нарушения на уровень промышленной безопасности и охраны труда технического устройства, сооружения или ОПО в целом;

- исходя из критерия важности и срочности определить приоритеты для установления сроков принятия корректирующих мep;

- оценить результативность осуществления производственного контроля на ОПО;

- организовать управление производственным контролем.

Указанная Методика прошла апробацию на ОПО нефтедобывающих производств и рекомендуется для применения отдельно или в составе карт контроля на таких ОПО, как фонды скважин, системы межпромысловых и промысловых трубопроводов, площадочные объекты подготовки и перекачки нефти.

\section{Список используемых источников}

1. Методика определения риск-ориентированного интегрального показателя промышленной безопасности (РОИП ПБ) / Утв. протоколом заседания Коллегии Федеральной службы по экологическому, технологическому и атомному надзору от 15.04.2016 г. № 1.

2. Климова И.В., Фатхутдинов Р.И. Контрольно-профилактические проверки как основа производственного контроля на опасных производственных объектах // Ресурсы Европейского Севера. Технологии и экономика освоения. 2017. № 1 (07). С. 29-36.

3. Колесников А.В., Морозова О.А. Использование рискориентированных интегральных показателей при определении уровня безопасности опасных производственных объектов // Промышленная и экологическая безопасность, охрана труда. 2015 . № 4 (101). С. 6-7. 
4. Кравчук И.Л., Гришин В.Ю., Смолин А.В. Риск негативных событий, обусловленный нарушениями требований безопасности, и способ его снижения. М.: Изд-во «Горная книга», 2015. 20 с.

5. Поздняков А.Н., Лежава С.А. Технический контроллинг в вопросах предупреждения аварийности и травматизма на энергетическом предприятии // Безопасность труда в промышленности. 2014. № 2. С. 62-67.

6. Смородова О.В., Китаев С.В., Сергеева К.В. Ранжирование технологических установок нефтепереработки по обобщенному критерию промышленной безопасности // Электронный научный журнал «Нефтегазовое дело». 2017. № 4. С. 165-179. URL: http://www.ogbus.ru/issues/4_2017/ogbus_4_2017_p165-179_SmorodovaOV_ru.pdf (дата обращения: 25.08.2017).

7. Фатхутдинов Р.И. Разработка и применение карт контроля для проведения проверок на опасных производственных объектах нефтегазодобывающих предприятий // Севергеоэкотех-2017: матер. XVIII Междунар. молодежной науч. конф. (г. Ухта, 12-14 апреля 2017 г.): в 6 ч. Ухта: ФБОУ ВО «УГТУ», 2017. Ч. 4. С. 57-61.

\section{References}

1. Metodika opredeleniya risk-orientirovannogo integral'nogo pokazatelya promyshlennoi bezopasnosti (ROIP PB) / Utv. protokolom zasedaniya Kollegii Federal'noi sluzhby po ekologicheskomu, tekhnologicheskomu i atomnomu nadzoru ot 15.04.2016 g. № 1. [Methodology for determining the risk-oriented integrated index of industrial safety (ROIP PB). Approved by Protocol of the Meeting of the Board of the Federal Service for Environmental, Technological and Nuclear Supervision dd. April 15, 2016 No. 1]. [in Russian]. 
2. Klimova I.V., Fatkhutdinov R.I. Kontrol'no-profilakticheskie proverki kak osnova proizvodstvennogo kontrolya na opasnykh proizvodstvennykh ob"ektakh [Control and Preventive Inspections as a Basis for Production Control at Hazardous Production Facilities]. Resursy Evropeiskogo Severa. Tekhnologii i ekonomika osvoeniya - Resources of the European North. Exploration Technologies and Economics, 2017, No. 1 (07), pp. 29-36. [in Russian].

3. Kolesnikov A.V., Morozova O.A. Ispol'zovanie risk-orientirovannykh integral'nykh pokazatelei pri opredelenii urovnya bezopasnosti opasnykh proizvodstvennykh ob"ektov [Use of Risk-Oriented Integral Indicators in Determining the Level of Safety of Hazardous Production Facilities]. Promyshlennaya i ekologicheskaya bezopasnost', okhrana truda - Industrial and Environmental Safety, Labor Protection, 2015, No. 4 (101), pp. 6-7. [in Russian].

4. Kravchuk I.L., Grishin V.Yu., Smolin A.V. Risk negativnykh sobytii, obuslovlennyi narusheniyami trebovanii bezopasnosti, i sposob ego snizheniya [The Risk of Negative Events Caused by Violations of Safety Requirements, and the Way to Reduce it]. Moscow, Gornaya kniga Publ., 2015. 20 p. [in Russian].

5. Pozdnyakov A.N., Lezhava S.A. Tekhnicheskii kontrolling v voprosakh preduprezhdeniya avariinosti i travmatizma na energeticheskom predpriyatii [Technical Controlling in Accidents and Injuries Prevention in Energy Company]. Bezopasnost' truda $\mathrm{v}$ promyshlennosti - Industrial Safety in Industry, 2014, No. 2, pp. 62-67. [in Russian].

6. Smorodova O.V., Kitaev S.V., Sergeeva K.V. Ranzhirovanie tekhnologicheskikh ustanovok neftepererabotki po obobshchennomu kriteriyu promyshlennoi bezopasnosti [The Technological Oil Refining Units Ranging on the Base of Industrial Safety Generalized Criteria]. Elektronnyi nauchnyi zhurnal «Neftegazovoe delo» - Electrinic Scientific Journal «Oil and Gas Business», 2017, No. 4, pp. 165-179. URL: http: //www.ogbus.ru/issues/ 4_2017/ogbus_4_2017_p165-179_SmorodovaOV_ru.pdf (data obrashcheniya: 25.08.2017). [in Russian]. 
7. Fatkhutdinov R.I. Razrabotka i primenenie kart kontrolya dlya provedeniya proverok na opasnykh proizvodstvennykh ob"ektakh neftegazodobyvayushchikh predpriyatii [Development and Application of Control Cards for Inspections at Hazardous Production Facilities of Oil and Gas Producing Enterprises]. Materialy XVIII Mezhdunarodnoi molodezhnoi nauchnoi konferentsii «Severgeoekotekh - 2017» (g. Ukhta, 12-14 aprelya 2017 g.): v 6 ch. [Materials of XVIII International Youth Scientific Conference «Severgeoekotech - 2017» (Ukhta, April 12-14, 2017): in 6 Ch. Ukhta, FBOU VO «UGTU», 2017, Ch. 4, pp. 57-61. [in Russian].

\section{Сведения об авторе}

\section{About the author}

Фатхутдинов Р.И., аспирант кафедры промышленной безопасности и охраны окружающей среды ФГБОУ ВО «Ухтинский государственный технический университет», г. Ухта, Российская Федерация

R.I. Fatkhutdinov, Undergraduate Student of Industrial Safety and Environmental Protection Department, FSBEI HE «Ukhta State Technical University», Ukhta, Russian Federation

E-mail: fatkhutdinov88@mail.ru 